CARADDE: Jurnal Pengabdian Kepada Masyarakat
$\begin{gathered}\text { https://journal.ilininstitute.com/index.php/caradde } \\ \text { Volume 2 I Nomor 1 I Agustus I2019 } \\ \text { e-ISSN: 2621-7910 dan p-ISSN: 2621-7961 }\end{gathered}$

\title{
Pelatihan Teknologi Budidaya Dan Rancang Bangun Mesin Pembelah Pinang
}

\section{Endang Sri Wahyuni ${ }^{1}$, Sunarto ${ }^{2}$}

\begin{tabular}{ll}
\hline \hline Keywords : & Abstrak. Tujuan dilaksanakannya Program Pengabdian \\
Pinang; & kepada masyarakat adalah untuk membantu mengatasi \\
Rancang Bangun; & permasalahan masyarakat di Desa Pambang Baru terutama \\
Mesin Pembelah Pinang. & Kelompok Tani Berkah dan Ibu - ibu PKK agar mampu \\
& meningkatkan efisiensi waktu pengolahan pinang. Jika waktu \\
Corespondensi Author & produksi semakin cepat, maka hasil yang didapatkan juga \\
Akuntansi Keuangan Publik, & semakin cepat. Luaran yang diharapkan dari program \\
Jalan Bathin Alam Politeknik Negeri & pengabdian kepada masyarakat ini diantaranya adalah \\
Bengkalis & terbentuknya kelompok usaha bersama (KUBE) di Desa \\
Email: endang.sri@polbeng.ac.id & Pambang Baru dengan membentuk perkebunan budidaya \\
& pinang secara komersil. Tahapan kegiatan yang akan \\
History Artikel & dilaksanakan berupa pengadaan/pembuatan mesin pembelah \\
Received: Juni-2019; & pinang, pelatihan dan workshop budidaya pinang secara \\
Reviewed: Juli -2019 & komersil. Hasil dari kegiatan pengabdian ini tercipta satu unit \\
Accepted: Agustus-2019 & alat mesin pembelah pinang, pelatihan dan workshop \\
Published: Agustus-2019 & budidaya dan pasca panen pinang dan pelatihan \\
& pengoperasian dan perawatan mesin pembelah pinang. \\
& Dengan adanya kegiatan pengabdian kepada masyarakat ini, \\
& pengetahuan masyarakat petani pinang bertambah dan alat \\
pembelah yang diberikan bisa membantu mempercepat proses & pembelahan pinang. \\
\hline \hline
\end{tabular}

(c) (1) This work is licensed under a Creative Commons Attribution

4.0 International License

\section{PENDAHULUAN}

Kabupaten Bengkalis adalah salah satu Kabupaten di Provinsi Riau. Wilayahnya mencakup daratan bagian Timur Pulau Sumatera dengan wilayah kepulauan, dengan luas adalah $7.793,93 \mathrm{~km}^{2}$. Jumlah produksi buah pinang di Bengkalis berkembang secara cepat dan di ekspor ke luar negeri, seperti Malaysia, India, Sri Lanka, dan Pakistan. Dalam hal tanaman tradisional Indonesia, tanaman pinang telah lama dikenal sebagai komoditas yang memiliki banyak manfaat. Selain digunakan sebagai pelengkap ramuan menyirih, tanaman pinang (Areca Catechu) juga dimanfaatkan menjadi ramuan untuk mengobati penyakit kudis, cacingan, disentri, batu ginjal, sariawan, mimisan, flu, koreng dan borok (Corner, 1966). Harga pinang dipasaran juga sangat stabil, sehingga pinang sangat bagus untuk dibudidayakan secara komersil.

Meskipun demikian masyarakat masih memiliki kekhawatiran untuk mengembangkan pinang ini sebagai pengahasilan utama mereka. Padahal prospek perkebunan pinang secara komersil memiliki prospek yang sangat besar kedepannya. Permasalahan yang masih menghambat produktivitas kelompok tani di Desa Pambang Baru adalah pengolahan pinang pasca panen yang membutuhkan waktu yang lama. Pengolahan buah pinang membutuhkan waktu antara 7-12 hari. Proses pengolahan pinang pasca panen dimulai dari 
Caradde: Jurnal Pengabdian Kepada Masyarakat Vol 2 No 1, Agustus 2019

proses pembelahan buah pinang, pekerja biasanya menggunakan pisau atau parang dan alat pembelah, dimana kemampuan belah dengan menggunakan pisau atau parang berkisar antara 20-25 buah/menit, kemudian proses pengeringan buah pinang dengan cara dijemur, setelah kering buah yang masih memiliki kulit ini dapat dicungkil bijinya dan dijemur kembali untuk mengurangi kadar airnya. Dari beberapa tahapan pengolahan pinang tersebut tahap pembelahan merupakan proses yang memakan waktu lama. Proses pembelahan masih menggunakan cara manual.

Permasalahan yang dihadapi oleh Kelompok Tani Berkah di Desa Pambang Baru Kec. Bantan Kab. Bengkalis diatas menginisiasi pengusul dari Politeknik Negeri Bengkalis untuk mencari solusi yaitu dengan memberikan penyuluhan dan pelatihan terkait budidaya pinang secara komersil, membuat alat pembelah pinang. Oleh karena itu, program pengabdian ini dilakukan untuk membuat rancang bangun terkait peralatan mesin pembelah pinang, pelatihan pengoperasian dan pemeliharaan mesin pembelah pinang, pelatihan budidaya pinang skala komersil. Keberadaan mitra nantinya akan sangat berpengaruh terhadap keberlangsungan model dan teknologi yang akan diterapkan di masyarakat.

\section{METODE}

Metode dalam kegiatan pengabdian kepada masyarakat untuk kelompok tani berkah dan ibu-ibu PKK di Desa Pambang Baru Kec Bantan, Kabupaten Bengkalis dibagi menjadi beberapa tahapan seperti yang diperlihatkan pada gambar.

Pelaksanaan kegiatan ini direncanakan dalam waktu 8 bulan, secara singkat gambaran pelaksanaan kegiatan yang dilakukan sebagai berikut: Pelaksanaan kegiatan yang bersifat administratif berupa kegiatan survei dan observasi ke lapangan sebagai bahan analisis permasalahan dan solusi pemecahannya. Setelah mendapat permasaalahan dari mitra dilanjutkan dengan pengajuan proposal ke Ristek Dikti. Setelah proposal diterima oleh pihak Ristek Dikti diadakan sosialisasi dan penyuluhan pada masyarakat sekaligus membuat kesepakatan bersama untuk merencanakan kegiatan, setelah itu langkah terakhir yang dilakukan ketua pengusul adalah memulai pembuatan mesin pembelah pinang (peralatan)

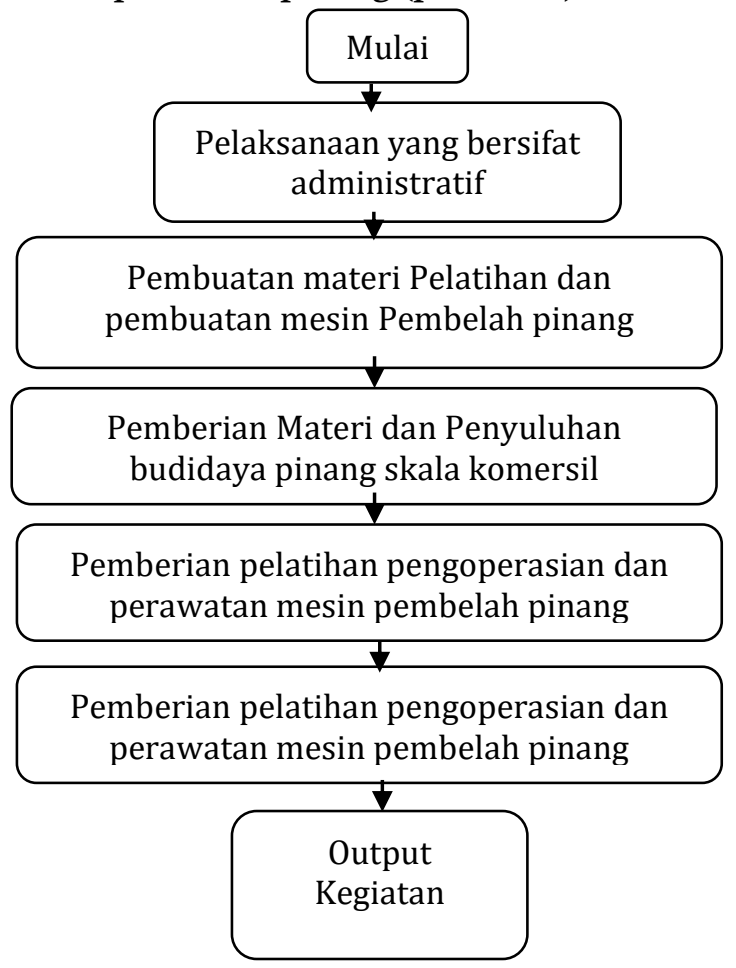

Gambar 1. Metode Pelaksanaan Pengabdian kepada masyarakat

Pada poin pembuatan materi pelatihan berisi tentang pembuatan modul pelatihan (dalam bentuk hardcopy) yaitu modul pengoperasian dan pemeliharaan mesin pembelah pinang dan modul pelatihan Optimasi penjualan pinang secara komersil. Tahap selanjutnya adalah persiapan pelatihan teknologi budidaya dan pasca panen inang dan realisasi kegiatan dengan menyiapkan segala hal peralatan dan bahan yang dibutuhkan, seperti sepanduk, alat tulis, konsumsi, ruangan, dan persiapan yang lain yang dibutuhkan. Pada tahap ini mitra diberi pelatihan teknologi budidaya pinang secara komersil. Setelah diadakan pelatihan untuk menambah pengetahuan budidaya dan pasca panen pinang, mitra diberikan pelatihan pengoperasian dan perawatan mesin pembelah pinang. Adapun outpun dari kegiatan ini nantinya berupa, terciptanya 1 unit mesin pembelah pinang, terbentuknya kelompok Unit Bersama (KUBE) budi daya pinang dan terakhir akan dilakukakn pendampingan dan evaluasi bersama terkait pelaksanaan program pengabdian kepada masyarakat kepada mitra. 


\section{HASIL DAN PEMBAHASAN}

Hasil yang dicapai pada program Pengabdian kepada masyarakat dintaranya adalah sosialisasi pengusul ke desa mitra, kemudian pengusul melakukan pelatihan teknologi budidaya dan pasca panen pinang, setelah itu pengusul membuat satu unit mesin pembelah pinang, pengusul juga mempublikasikan hasil penelitian di media cetak dan online. Selain itu luaran lainnya yang akan dilaksanakan adalah serah terima dan pelatihan pengoperasian dan perawatan mesin pembelah pinang, submit di jurnal nasional, serta melakukan pendampingan ke kelompok mitra.

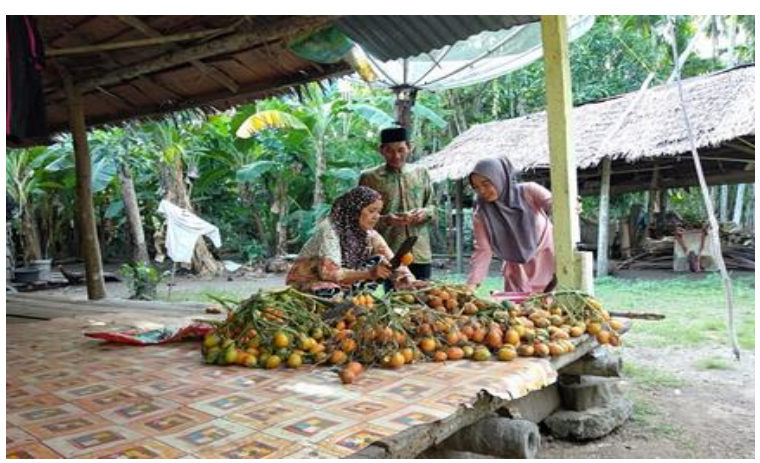

Gambar 2. Pembelahan buah pinang secara manual
1. Pelatihan Teknologi Budidaya dan Pasca Panen Pinang

Ada pun salah satu luaran yang ingin dicapai ketua pelaksana pada program pengabdian masyarakat ini adalah masyarakat bisa lebih mengetahui cara budidaya pinang yang baik, kemudian cara pengolahan pasca panen, agar nantinya bisa lebih mengembangkan pinang petani secara komersil.

Pada acara pelatihan ini dihadiri oleh tokoh masyarakat RT, RW, dusun dan kelompok mitra serta ibu-ibu PKK. Dari pihak tim menghadirkan narasumber dari petugas pendamping pertanian dari dinas pertanian kabupaten bengkalis. Banyak hal yang disampaikan oleh narasumber dimulai dari morfologi pinang, cara penanaman pinang yang baik, pengolahan lahan dan proses pengolahan pinang pasca panen. Gambar 3 menunjukkan hasil pelatihan budidaya dan pasca panen pinang. Dari hasil pelatihan ini masyarakat menjadi lebih mengetahui bagaimana budidaya pasca panen pinang yang baik.
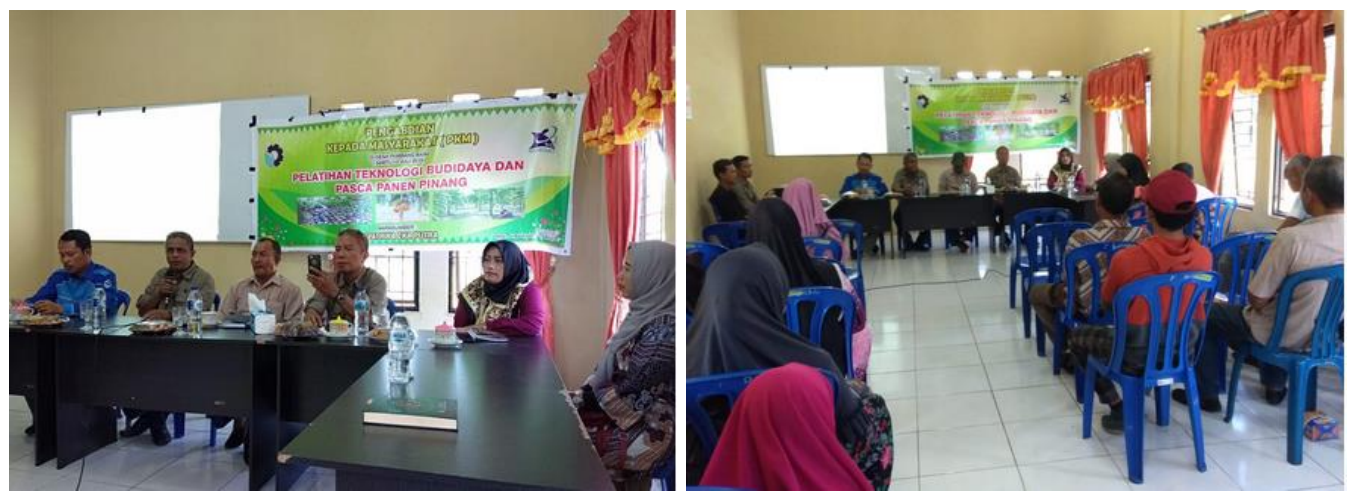

Gambar 3. Tim memberikan materi dalam pelatihan budidaya dan pasca panen pinang

\section{Produk Mesin Pembelah Pinang}

Pada program pengabdian kepada masyarakat ini juga tim menghasilkan sebuah produk teknologi tepat guna yaitu berupa mesin pembelah pinang. Mesin ini dibuat menggunakan penggerak motor diesel dengan kapasitas 200-300 kg/jam. Berdasarkan hasil pengujian Rodika (2018) didapat gaya tekan yang diperlukan dalam membelah buah pinang adalah diambil gaya terbesar yaitu 50 kg. Mesin ini terdiri dari beberapa bagian antara lain: bentuk hopper trapesium, system pembelahan menggunakan dua pembelah (pisau berputar vertikal), sistem tranmisi menggunakan kopling, pulley dan belt, dan roda gigi. Cara kerjanya adalah motor penggerak diesel akan hidup dan berputar, kemudian putaran tersebut diteruskan oleh pulley, setelah itu diteruskan lagi oleh pulley dan belt, kemudian diteruskan lagi oleh roda gigi. Berputaran pulley dan belt menyebabkan mata potong berputar, kemudian rotor pembawa berputar karena putaran pada roda gigi.kemudian pinang dimasukkan melalui 
hopper. Pada saat uji coba uji coba pertama dilakukan, hasil pembelahan kurang rapi. Kemudian diperbaiki pada bagian mata pengantarnya. Setelah itu sistem pembelahannya berlangsung baik.

pada tahap ini juga masyrakat akan diberikan pelatihan cara pengoperasian dan perawatan mesin pembelah pinang. Dengan adanya mesin ini bisa dimanfaatkan kelompok mitra dan masyarakat pada umumnya agar proses pengolahan pasca panen bisa lebih cepat dari cara manual. Gambar 4 memperlihatkan mesin pembelah pinang yang dibuat oleh tim pelaksana kegiatan pengabdian kepada masyarakat.

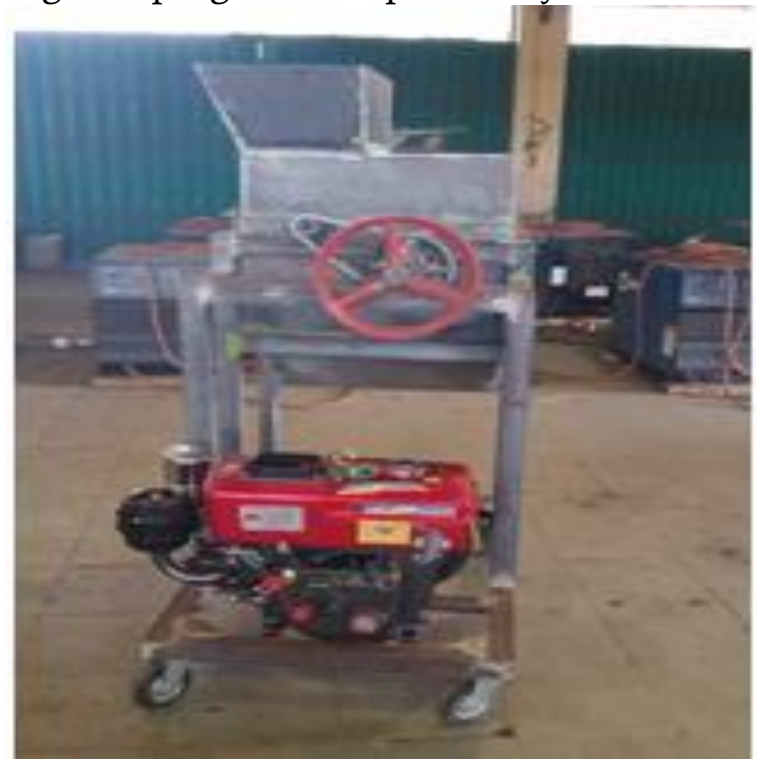

Gambar 4. Mesin Pembelah Pinang

3. Pembentukan Kelompok Usaha Bersama

Keluaran dari pengabdian ini juga menghasilkan pembentukan kelompok usaha bersama dibidang pinang untuk pengembangan budidaya pinang kedepannya. Dalam hal ini juga kelompok yang dibentuk diberikan pengetahuan yang lebih rinci tentang budidaya pinang. Untuk kegiatan awal kelompok ini akan mempromosikan mesin pembelah pinang secara keliling dan menawarkan jasa pembelahan pinang kemasyarakat secara umum diluar kelompok. Selain itu juga kelompok ini akan membeli pinang dari para petani dengan harga yang lebih baik. Untuk kedepannya kelompok yang telah terbentuk akan melengkapi peralatan dan perlengkapan budidaya dan pembukaan kebun untuk budidaya lebih banyak lagi.

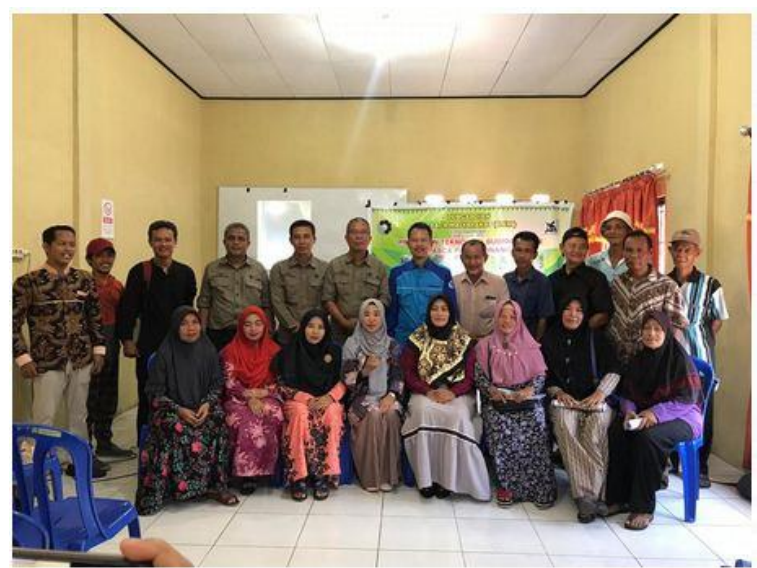

Gambar 5. Kelompok Usaha Pinang (KUBE)

\section{SIMPULAN DAN SARAN}

Dari Program pengabdian kepada masyarakat yang telah dilaksanakan oleh tim pelaksana dapat disimpulkan bahwa ada beberapa hasil yang telah dicapai oleh pelaksana kegiatan: (1) Pelatihan teknologi budidaya dan pasca panen pinang; (2) dihasilkan produk teknologi tepat guna berupa mesin pembelah pinang; (3) dibentuk kelompok usaha bersama untuk mengembangkan pinang secara komersil

Adapun saran untuk pengbdian kedepannya, ketua pelaksana kegiatan ingin melanjutkan proses budidaya ini dengan menambah beberapa peralatan penunjang produksi budidaya dan pasca panen. Kemudian pembudidayaan pinang dengan memanfaatkan lahan masyarakat yang banyak tidak terpakai.

\section{DAFTAR RUJUKAN}

Anonim. 1985. Arecanut package of practice. Central Plantation Crops Research Institute. Kerala. India.

Meyanto, E., R.A. Susidarti, S. Handayani, dan F. Rahmi. 2008. Ekstrak etanolik biji buah pinang (Areca catechu L.) mampu menghambat proliferasi dan memacu apoptosis sel MCF-7. Majalah Farmasi Indonesia. 19 (1) : 12-19.

Novarianto H., dan Z. Mahmud. 1988. Pinang sebagai komoditi ekspor masa depan. Buletin Balitka No. 
Wahyuni, Sunarto. Rancang Bangun Mesin Pembelah Pinang

5\&6. Mei-September.

Saleh, F. M. (2014). RE-DISAIN ALAT PEMBELAH BUAH PINANG BERBASIS ERGONOMI MAKRO MELALUI

PENDEKATAN'SHIP'(Studi Kasus di Kecamatan Keritang-Inhil). Jurnal Teknik Industri Universitas Bung Hatta, 2(1).

ILHAM， NURYADIN (2017) Rancang Bangun Alat Pembelah Buah Pinang (Areca

catechu L.) Tipe Tang. Diploma thesis, Universitas Andalas

Rodika, R., Tuparjono, T., Otomo, B., \& Febryani, R. A. (2018). Rancangan Mesin Pembelah Buah Pinang Dengan Dua Mata Potong. Manutech: Jurnal Teknologi Manufaktur, 10(02), 59-63.

Erizal, I. P., Yetri, Y., \& Nusyirwan, N. (2018). Perencanaan Perawatan Mesin Pengupas Kulit Pinang. Jurnal Teknik Mesin, 11(1), 11-15.

Thamrin, M., Herman, S., \& Hanafi, F. (2015). Pengaruh faktor sosial ekonomi terhadap pendapatan petani pinang. AGRIUM: Jurnal Ilmu Pertanian, 17(2).

Mustika, S., Fathurrahman, F., Mahfudz, M., \& Saleh, M. S. (2010). Perkecambahan benih pinang pada berbagai cara penanganan benih dan cahaya. Agroland, 17(2). 